\title{
Cultured Ostreococcus is cobalamin-independent
}

Mark Paul Pašek

2455 Rice Boulevard

Houston, TX 77005 USA

saltwateralgae@yahoo.com

\begin{abstract}
The marine microalga Ostreococcus is considered to depend on the methionine synthase METH and its methylated cobalamin cofactor for methionine synthesis because it lacks METE, the methylcobalamin-independent methionine synthase. Here I describe minimal media lacking both biotin and cobalamin yet suitable for growth of cultured Ostreococcus.
\end{abstract}

\section{Keywords}

Ostreococcus; METE; METH; minimal medium; gellan gum; METE selection; biotin; cobalamin; methionine; bacterioplankton

\section{Introduction}

The marine unicellular alga Ostreococcus has evolved clades A, B, and C, each with sequenced representatives, as well as clade D, Ostreococcus mediterraneus (Subirana et al., 2013). The model of methionine biosynthesis in Ostreococcus states that METH [methylcobalamindependent] is the sole methionine synthase and is based on the identification of the gene encoding METH in all three clades. In addition, the gene encoding METE [5-

methyltetrahydrofolate-dependent; cobalamin-independent] appears missing for all three clades, leading to the prediction of cobalamin-dependent growth (Helliwell et al., 2011). These observations suggest that if Ostreococcus cells were transformed with synthetic DNA designed to express METE, transformants would utilize the endogenous METH substrate 5methyltetrahydofolate to synthesize methionine and could be selected in minimal medium in the absence of cobalamin.

\section{Materials and Methods}

Ostreococcus cell cultures were obtained from the Roscoff Culture Collection, Roscoff, France, and the Provasoli-Guillard National Center for Marine Algae and Microbiota, East Boothbay, Maine, USA. Panels of candidates to be evaluated for DNA transformation were assembled. The panel for clade A consisted of NCMA2972 (Palenik et al., 2007), RCC754, RCC755, and 
RCC756. The panel for clade C included RCC614 and RCC745 (Derelle et al., 2006). The members of the panel for clade D were RCC789, RCC1107, RCC1119, and RCC1121.

Ostreococcus cells were cultured in suspension by rocking under continuous blue illumination in minimal medium at room temperature. Minimal medium is artificial seawater (McDonald et al., 2010) supplemented with $0.9 \mathrm{mM} \mathrm{NaNO}_{3}, 100 \mu \mathrm{M} \mathrm{Na} \mathrm{EDTA}_{2} \cdot 2 \mathrm{H}_{2} \mathrm{O}, 10 \mu \mathrm{M} \mathrm{NaH} \mathrm{PO}_{4} \cdot \mathrm{H}_{2} \mathrm{O}, 10$ $\mu \mathrm{M}$ FeNaEDTA, $0.9 \mu \mathrm{M} \mathrm{MnCl}_{2} \bullet 4 \mathrm{H}_{2} \mathrm{O}, 300 \mathrm{nM}$ thiamine $\bullet \mathrm{HCl}, 100 \mathrm{nM} \mathrm{Na} \mathrm{SeO}_{3}, 80 \mathrm{nM}$ $\mathrm{ZnSO}_{4} \cdot 7 \mathrm{H}_{2} \mathrm{O}, 30 \mathrm{nM} \mathrm{Na}{ }_{2} \mathrm{MoO}_{4} \cdot 2 \mathrm{H}_{2} \mathrm{O}$, and $10 \mathrm{nM} \mathrm{CuSO}_{4} \cdot 5 \mathrm{H}_{2} \mathrm{O}$. This list of supplements is simplified from that formulated by Keller (Keller et al., 1987), most notably lacking biotin, cyanocobalamin, $\mathrm{CoSO}_{4} \cdot 7 \mathrm{H}_{2} \mathrm{O}, \mathrm{NH}_{4} \mathrm{Cl}$, and tris(hydroxymethyl)aminomethane. In addition, the selenite concentration is $10 \mathrm{nM}$ in Keller medium.

For polymerase chain reaction DNA amplification, template DNA was prepared with QuickgDNA $^{\mathrm{TM}}$ from Zymo Research, PCR primer pairs were synthesized by Integrated DNA Technologies, and targets were amplified with the Q5 DNA polymerase from New England BioLabs.

\section{Results}

Using DNA from RCC614 and RCC745 as template and two primer pairs for each of the two targets $M E T H$ and $U R A 5 / 3$, polymerase chain reaction DNA amplification yielded in each case DNA fragments of the predicted size, and authenticated cell culture identity as Ostreococcus after long-term serial culture in minimal medium with 400 pM cobalamin. For NCMA2972, a primer pair also targeting URA5/3 was used (Table 1).

Minimal medium with cobalamin supported extended serial growth for each cell culture in each clade. In addition, minimal medium containing cobalamin and solidified with $0.125 \%$ gellan gum (Sigma-Aldrich) supported diverse green bacterioplanktonic surface growth (Figure 1) for each cell culture in each clade, with the exception of NCMA2972.

As a transformation host, RCC614 was chosen. Mock transformation experiments, without synthetic DNA, were designed to quantitate and evaluate background growth on solidified minimal medium lacking cobalamin. RCC614 suspension cells were cultured in minimal medium with $400 \mathrm{pM}$ cobalamin. $10^{6}$ cells $(100 \mu \mathrm{l})$ were mixed with $50 \mu \mathrm{l} \mathrm{CutSmart}{ }^{\circledR}$ restriction enzyme buffer [50 $\mathrm{mM}$ potassium acetate-10 $\mathrm{mM}$ magnesium acetate-20 $\mathrm{mM}$ tris(hydroxymethyl)aminomethane acetate (pH 7.9)-100 $\mu \mathrm{g} / \mathrm{ml}$ bovine serum albumin; New England BioLabs], layered onto $100 \mu \mathrm{l}$ protoplast transformation buffer [100 mM CaCl $2-200$ mM mannitol-40\% PEG4000; Yoo et al., 2007], briefly vortexed, incubated for 5 minutes at room temperature, diluted into $10 \mathrm{ml}$ of minimal medium containing $20 \mathrm{pM}$ cobalamin, and cultured for 24 hours. Cells were then aerosolized onto minimal media lacking cobalamin solidified with $0.125 \%$ gellan gum at a density of $10^{5}$ cells per $90 \mathrm{~mm}$ plate $(20 \mathrm{ml}$ solid media per plate). After 10 days at room temperature, approximately 10 to 20 green bacterioplanktonic colonies per plate emerged at normal growth rates.

Twelve cobalamin-independent colonies were picked into minimal medium without cobalamin and cultured; all cultured remained cobalamin-independent after more than 10 serial passages (1/200 dilution/passage). Each cobalamin-independent culture was authenticated as RCC614 by 
polymerase chain reaction DNA amplification using the primer pair for URA5/3 listed in Table 1 which yields a 3207 bp diagnostic fragment (Figure 2).

It is concluded that cobalamin-independent Ostreococcus colonies are obtained at a frequency of approximately $0.01 \%$ when selected on gellan gum-solidified minimal medium without cobalamin.

\section{Discussion}

The utility of METE as a positive selection marker relies on a cobalamin-dependent Ostreococcus transformation recipient. RCC614 is a representative co-culture of Ostreococcus and various phycosphere-associated marine bacteria (Abby et al., 2014; Lupette et al., 2016). The bacteria may supply biotin, cobalamin, and methionine to the Ostreococcus phycosphere. A mock transformation as described above of RCC614 will yield Ostreococcus bacterioplanktonic colony growth on minimal medium with no added biotin and cobalamin, as observed. Only a cobalamin-dependent Ostreococcus cell culture, not necessarily biotin-independent, is required to implement the use of METE as a positive selection marker.

Both RCC614 and Ostreococcus RCC809 (Grigoriev, 2011; clade B) lack the gene encoding the algal-specific cobalamin acquisition protein 1, whereas NCMA2972 has it (Bertrand et al., 2012). Perhaps Ostreococcus clades C and B obtain methionine from their phycosphere while clade A can utilize cobalamin in addition.

\section{References}

Abby, S.S., Touchon, M., De Jode, A., Grimsley, N., Piganeau, G., 2014. Bacteria in Ostreococcus tauri cultures - friends, foes, or hitchhikers? Frontiers in Microbiology 5, Article 505.

doi: 10.3389/fmicb.2014.00505

Bertrand, E.M., Allen, A.E., Dupont, C.L, Norden-Krichmar, T.M., Bai, J., Valas, R.E., Saito, M.A., 2012. Influence of cobalamin scarcity on diatom molecular physiology and identification of a cobalamin acquisition protein. PNAS 109 (26), E1762-E1771.

doi: 10.1073/pnas.1201731109

Derelle, E., Ferraz, C., Rombauts, S., Rouzé, P., Worden, A.Z., Robbens, S., Partensky, F., Degroeve, S., Echeynié, S., Cooke, R., Saeys, Y., Wuyts, J., Jabbari, K., Bowler, C., Panaud, O., Piégu, B., Ball, S.G., Ral, J-P., Bouget, F-Y., Piganeau, G., De Baets, B., Picard, A., Delseny, M., Demaille, J., Van de Peer, Y., Moreau, H., 2006. Genome analysis of the smallest free-living eukaryote Ostreococcus tauri unveils many unique features. PNAS 103 (31), 11647-11652.

doi: 10.1073/pnas.0604795103 
Grigoriev, I.V., Nordberg, H., Shabalov, I., Aerts, A., Cantor, M., Goodstein, D., Kuo, A., Minovitsky, S., Nikitin, R., Ohm, R.A., Otillar, R., Poliakov, A., Ratnere, I., Riley, R., Smirnova, T., Rokhsar, D., Dubchak, I., 2012. The Genome Portal of the Department of Energy Joint Genome Institute. Nucleic Acids Research 40 (D1), D26-D32.

doi: 10.1093/nar/gkr947

Helliwell, K.E., Wheeler, G.L., Leptos, K.C., Goldstein, R.E., Smith, A.G., 2011. Insights into the Evolution of Vitamin B12 Auxotrophy from Sequenced Algal Genomes. Mol. Biol. Evol. 28(10), 2921-2933.

doi: $10.1093 / \mathrm{molbev} / \mathrm{msr} 124$

Lupette, J., Lami, R., Krasovec, M., Grimsley, N., Moreau, H., Piganeau, G., Sanchez-Ferandin, S., 2016. Marinobacter Dominates the Bacterial Community of the Ostreococcus tauri Phycosphere in Culture. Frontiers in Microbiology 7, Article 1414.

doi: 10.3389/fmicb.2016.01414.

Keller, M.D., Selvin, R.C., Claus, W., Guillard, R.R.L., 1987. Media for the culture of oceanic ultraphytoplankton. J. Phycol. 23, 633-638.

doi: 10.1111/j.1529-8817.1987.tb04217.x

McDonald, S.M, Plant, J.N., Worden, A.Z., 2010. The Mixed Lineage Nature of Nitrogen Transport and Assimilation in Marine Eukaryotic Phytoplankton: A Case Study of Micromonas. Mol. Biol. Evol. 27(10), 2268-2283.

doi: $10.1093 / \mathrm{molbev} / \mathrm{msq} 113$

Palenik, B., Grimwood, J., Aerts, A., Rouzé, P., Salamov, A., Putnam, N., Dupont, C., Jorgensen, R., Derelle, E., Rombauts, S., Zhou, K., Otillar, R., Merchant, S.S, Podell, S., Gaasterland, T., Napoli, C., Gendler, K., Manuell, A., Tai, V., Vallon, O., Piganeau, G., Jancek, S., Heijde, M., Jabbari, K., Bowler, C., Lohr, M., Robbens, S., Werner, G., Dubchak, I., Pazour, G.J., Ren, Q., Paulsen, I., Delwiche, C., Schmutz, J., Rokhsar, D., Van de Peer, Y., Moreau, H., Grigoriev, I.V., 2007. The tiny eukaryote Ostreococcus provides genomic insights into the paradox of plankton speciation. PNAS 104 (18), 7705-7710.

doi: 10.1073/pnas.0611046104

Subirana, L., Péquin, B., Michely, S., Escande, M-L., Meilland, J., Derelle, E., Marin, B., Piganeau, G., Desdevises, Y., Moreau, H., Grimsley, N.H., 2013. Morphology, Genome Plasticity, and Phylogeny in the Genus Ostreococcus Reveal a Cryptic Species, O. mediterraneus sp. nov. (Mamiellales, Mamiellophyceae). Protist 164, 643-659.

doi: 10.1016/j.protis.2013.06.002

Yoo, S-D., Cho, Y-H., Sheen, J., 2007. Arabidopsis mesophyll protoplasts: a versatile cell system for transient gene expression analysis. Nature Protocols 2 (7), 1565-1572.

doi: 10.1038/nprot.2007.199 


\section{Table 1}

List of PCR primer pairs, DNA sequences, and DNA product sizes

for RCC614 and RCC745 (Ostreococcus tauri):

METH 5'.f GGGGCAGATTTTGTACATTAGCAGTAA

1068 bp

METH 5’.r AAAACCTAGAGTATGTGCGATGGACATGGGGTCGACGAACTCCTTGTAAGTC

METH 3'.f CGCGCCGAATATGGGAAAGAGTAGAAGCAGCGTATTTACTTAGTCTATTTCTTTTTAAAAG. 1024 bp

METH 3'.r CGCAGTTACCGGATGAGGATG

URA5/3.f TATCGCATGCGCTTTGCAT

3689 bp

URA5/3.r TGAAAGTGGAGAAGGTTCCGGACT

URA5/3.f CAGCGGCCTGCAGGAAATGAGAAG

3207 bp

URA5/3.r CTCGAGCTTTTGAACCAACTCGACGGTTT

for NCMA2972 (Ostreococcus lucimarinus):

URA5/3.f GTCTAGAGCTTGATTTCCACGTCAACC

4039 bp

URA5/3.r GAGGAATTGCACATGTTGCAGGA 


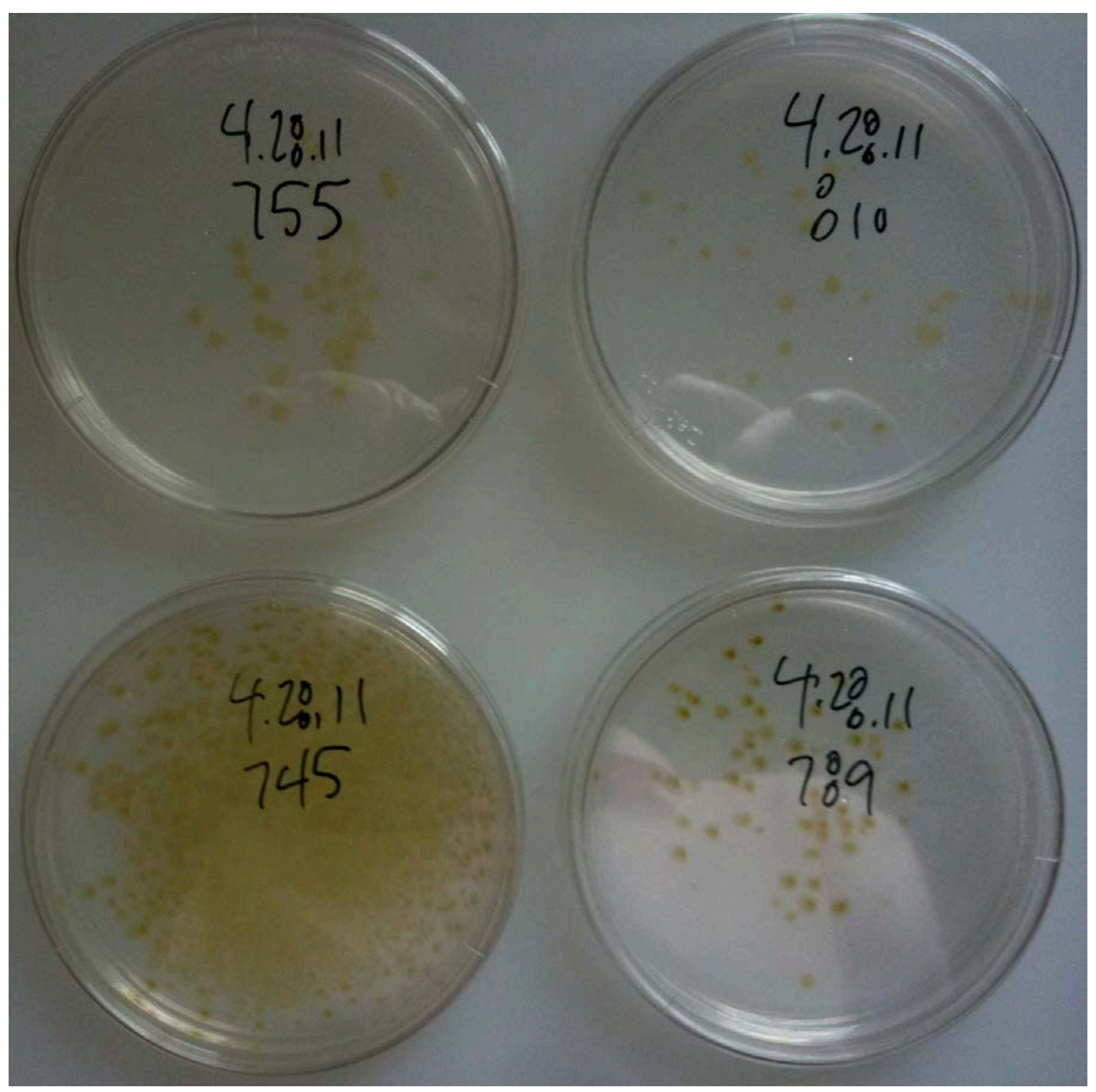

Figure 1. Bacterioplanktonic growth of Ostreococcus clades A, C, and D on minimal medium with cobalamin solidified with $0.125 \%$ gellan gum. 
Figure 2. PCR authentication of cobalamin-independent clones as Ostreococcus tauri RCC614.

Lanes 1-6 and 9-14 correspond to cobalamin-independent clones isolated on gellan gumsolidified minimal medium lacking cobalamin. Lane 8 is RCC614. Lane 7 is the Mass DNA ladder from New England BioLabs. The diagnostic 3207 bp DNA fragment is synthesized with a primer pair targeting the URA5/3 locus (Table 1). 